\title{
O papel do professor de línguas como um agente interculturalista e humanizador em um contexto de ensino de português língua estrangeira: implicações para a formação docente
}

\author{
Marta Lúcia Kfouri-Kaneoya \\ Universidade Estadual Paulista "Júlio de Mesquita Filho" \\ São José do Rio Preto \\ ml.kfouri@hotmail.com
}

\section{Resumo}

Neste artigo, discutimos a formação de professoras de línguas atuantes em um projeto de extensão de português língua estrangeira (PLE), oferecido a estrangeiros inseridos em um contexto brasileiro de imersão acadêmica. Propomo-nos a investigar o papel do professor de línguas, a partir de uma diretriz comunicativo-humanizadora de ensino/aprendizagem. Os dados da pesquisa constituem-se de reuniões pedagógicas gravadas, realizadas semanalmente entre a coordenadora e professores do projeto, no sentido de se analisar o processo de reflexão docente em busca da promoção de uma prática humanizadora em sala de aula, do bem-estar, da valorização de uma comunicação criativa, do esclarecimento dos choques culturais e do desenvolvimento de uma competência linguístico-cultural nos estrangeiros aprendizes de PLE. Tais reuniões são tomadas como ambiente potencial para a formação inicial docente crítico-humanizadora de professoras de PLE, já que sua formação acadêmica não contemplou a possibilidade de atuarem no ensino de sua língua materna como estrangeira. Os resultados também sugerem que as práticas discursivas das professoras podem, de fato, promover um ambiente humanizador de ensino/aprendizagem de PLE.

Palavras-chave: português língua estrangeira; contexto acadêmico; formação intercultural e humanizadora do professor de línguas

\section{Abstract}

In this article, we discuss the education process of language teachers in a Portuguese as a foreign language (PFL) institutional project, which is offered to foreigner students in a Brazilian context of academic immersion. We aim at investigating the role of language teachers from a communicative and 
humanizing teaching and learning approach. The research data are constituted by the recordings of pedagogical meetings between the coordinator and the teachers from the project, in order to analyze the teachers' reflective process in search of promoting some aspects such as a humanizing practice, the students' well-being, the valorization of creative communication, the comprehension of intercultural impacts and the linguistic and cultural development of foreign students' competence in classroom. Such meetings are held as a potential environment to a critical and humanizing PFL teachers education process, since they do not have this kind of education during their under graduation course. The results also suggest that the PFL teachers' discursive practice can, indeed, promotes a humanizing PFL teaching and learning environment.

Keywords: Portuguese as foreign language; academic context; intercultural and humanizing language teacher education

\section{Introdução}

Os trabalhos em torno da área de ensino de português língua estrangeira (PLE) constituem um terreno crescente de pesquisas a respeito do ensino/aprendizagem dessa língua para falantes de outros idiomas ${ }^{1}$. Para Almeida Filho $(2004 ; 2007)$, atuar nessa área significa "estudar os processos de ensinar e aprender PLE em distintos e específicos contextos" (2007, p. 34).

Por outro lado, reconhecemos que a temática da formação do professor de PLE ainda é um tema de poucos debates e reflexões no Brasil, no sentido de que as licenciaturas passem a se preocupar com a questão de que o futuro professor, nos dias atuais, poderá de fato ensinar nesse contexto - haja vista o crescente número de oportunidades para essa atividade tanto dentro quanto fora do país. Por essa razão, a formação do professor de PLE, tal como de um professor de línguas em geral, beneficia-se dos conhecimentos sobre o próprio processo de ensino/aprendizagem, sobre a natureza de uma língua não materna, sobre a cultura em que se insere a língua-alvo e a sua aprendizagem. De acordo com Cunha (2007), devemos ter claras as

\footnotetext{
${ }^{1} \mathrm{O}$ termo língua estrangeira é atribuído ao português ensinado como outra língua, de acordo com a SIPLE - Sociedade Internacional de Português Língua Estrangeira.
} 
peculiaridades desse ensino e do contexto em que se estabelece, bem como refletir sobre a problemática da formação de professores para a área.

Neste artigo, discutimos como a formação docente se configura em um projeto de ensino de PLE oferecido, inicialmente (a partir do $1^{\circ}$ semestre de 2012), como cursos de difusão do conhecimento a alunos estrangeiros provenientes de distintos países, em situação de intercâmbio acadêmico no Brasil (imersão), cursando graduação e pósgraduação em cursos diversos, em um campus de uma universidade pública do interior paulista.

\section{Projeto de Extensão Português Língua Estrangeira}

Atualmente, o projeto de extensão Português Língua Estrangeira tem por público-alvo não somente os estudantes universitários, mas também estrangeiros de diferentes nacionalidades, residentes no município e região onde a universidade está inserida, e que desejam ou têm necessidades de conhecer/ampliar conhecimentos sobre/na língua portuguesa e cultura brasileira. De maneira geral, o Projeto PLE pode contribuir com a formação de todos os envolvidos, por meio da integração universidade e demandas sociais (universalização do ensino); da possibilidade de formação docente, de ampliação de sua visão de mundo e de seu conhecimento; do diálogo com outras línguas e culturas; da prática de uma abordagem comunicativo-humanizadora de ensino; da possibilidade de geração de pesquisas relativas ao ensino e à formação docente em PLE, sob o prisma da Linguística Aplicada (LA). Portanto, o projeto tem grande potencial de divulgação da instituição, da cidade e da região ${ }^{2}$.

Nesse contexto multicultural, verificamos uma quebra de fronteiras geográficas e ideológicas, na qual estrangeiros de diversas partes do mundo deixam seus territórios de origem para organizar suas vidas temporariamente em outro território, algo que Mota (2010) chama de processos de desterritorialização e consequentes reterritorializações (p. 49). Isso não significa o apagamento de

\footnotetext{
${ }^{2}$ Coordeno esse projeto junto ao Departamento de Educação com o apoio da PROEX.
} 
culturas ou de línguas, mas, ao contrário, a redescoberta dos valores e das identidades culturais de origem do aprendiz, à medida que este ativa múltiplos olhares sobre os espaços e as culturas estrangeiras, o mesmo devendo ocorrer com o professor. Além disso, por frequentemente viajarem pelo Brasil enquanto realizam seus estudos acadêmicos, esses estrangeiros podem perceber como essa diversidade se constrói dentro da cultura de um país com dimensões continentais e trazer contribuições para o ensino e a aprendizagem que, muitas vezes, o professor poderia deixar de oferecer - não raro, os estrangeiros acabam conhecendo regiões e culturas brasileiras que o próprio professor, brasileiro, desconhece. Assim, os professores do projeto têm o desafio criativo de lidar com o ensino de sua LM como estrangeira, ao mesmo tempo em que enfrentam o próprio desconhecimento linguístico-cultural em relação a estrangeiros vindos da Índia, China ou Síria, por exemplo ${ }^{3}$. Reafirmamos, então, tratar-se de um contexto em que se ensina PLE ao mesmo tempo em que se forma o professor para isso, sob uma pedagogia multicultural, entendida como aquela que valoriza a voz do professor e do aluno como sujeitos e promove o dialogismo, permitindo a "construção do conhecimento de forma multidimensional” (MOTA, 2010).

\section{A formação do professor de línguas como um agente interculturalista e humanizador em um contexto multicultural}

Por não ser possível delegar somente ao docente a tarefa de falar sobre a língua, já que os aprendizes também precisam compreender e expor seus pontos de vista a respeito da heterogeneidade de culturas, povos, línguas e linguagens, acreditamos que o papel do professor passa a ser o de articulador de muitas vozes, variedades linguísticas e culturais (KFOURI-KANEOYA, 2008), que devem aparecer contextualmente, compartilhando com alunos estrangeiros a língua que

\footnotetext{
${ }^{3}$ Nos dois últimos semestres, o projeto tem acolhido número significativo de estrangeiros da comunidade externa à Universidade, refugiados de guerras civis e de epidemias, que vêm à região em busca de novas condições de vida e que têm um conhecimento muito rudimentar da língua portuguesa.
} 
ensina em funcionamento e refletindo com eles sobre as variações linguísticas e culturais existentes em seu país, tal como ocorre no país de origem desses estudantes.

Portanto, o professor nesse contexto é o de agregador de identidades culturais. Defendemos, pois, a ideia de se pensar no estabelecimento de uma linguagem humanizadora (GOMES DE MATOS, 2010), promovida pelo professor por meio de uma percepção intercultural de formação e atuação docente, que valoriza a comunicação criativa, minimiza, esclarece e contextualiza os choques culturais, promovendo a competência linguístico-cultural.

Em um contexto de ensino de PLE no qual predomina, obviamente, a interculturalidade, mas que se caracteriza como multicultural, aprendizes devem contribuir com as competências linguístico-comunicativas que já possuem em suas línguas e culturas de origem, para construir competências em relação à nova língua. Aprender e ensinar PLE, nesse contexto, significa levar em consideração valores universais que devem perpassar todas as línguas e culturas: o direito de todos de aprender qualquer língua, o senso de pertencimento e de identidade e a diversidade linguístico-cultural (UNESCO, 1996; MURPHEY et al., 2010). Trata-se de um processo de comunicar-se para o bem, observando-se os efeitos positivos da comunicação. Proporciona-se, nesse ambiente, um processo de humanização da educação, de reorganização da identidade multicultural e um reajuste das concepções de mundo, ao mesmo tempo em que se promove a formação do professor e do aluno como agentes humanizadores.

O professor, então, tem como reponsabilidade aproveitar adequadamente as competências dos aprendizes quanto àquilo que já conhecem (ou não) do português; valorizar o conhecimento e a experiência educacional prévios em suas línguas e países de origem; conhecer seus objetivos e expectativas para com a nova língua e no novo espaço de convivência social, ao mesmo tempo em que passa a utilizar sua LM com cuidado, a fim de proporcionar uma aprendizagem adequada e significativa. Desenvolve-se, assim, uma consciência metalinguística, proporcionada, sobretudo, pelo fato de ter de pensar mais sobre sua LM para ensiná-la a falantes de línguas diversas (LITTLE, 2002). 
Fairclough (2001) salienta que todos os indivíduos possuem certo senso de compreensão a respeito não só de como fazer aquilo que podem linguisticamente, mas também quanto a alguns questionamentos sobre os tipos de discurso, as posições subjetivas a serem assumidas e a (des)valorização social de sua LM em comparação a outras, por exemplo. Nesse sentido, o aprendiz precisa manifestar-se discursivamente a respeito desses fatores, a fim de capacitar-se a refletir, sistematizar e explicar sua própria experiência de linguagem. Também não podemos deixar de mencionar o fato de que as pessoas, hoje, veem o mundo de formas variadas, por conta das profundas mudanças contemporâneas e seus efeitos em sociedade. $\mathrm{O}$ fato de termos mais pessoas tendo oportunidades de sair de seus países para realizar sonhos acadêmicos, por exemplo, é reflexo dessas transformações de poder. Para o autor, o terreno de dominação deixou de ser nacional para ampliar-se em global, permitindo, inclusive, o deslocamento dessas pessoas para outros países, ou seja, que elas também administrem esse poder sobre suas próprias escolhas. Em sala de aula, mesmo onde o foco de análise é nacional ou local, é papel do professor mediador de multiculturas promover uma base humanizadora para a discussão de questionamentos internacionais, prevalecendo uma dialética entre o global e o nacional/local.

\section{Metodologia da investigação}

Para compreender as questões expostas acima, investigamos, de forma qualitativa e interpretativista (ANDRÉ, 2000) a formação do discurso humanizador das professoras envolvidas no Projeto de Extensão PLE, a partir das reflexões críticas construídas por elas nas reuniões pedagógicas semanais do projeto, em torno de suas práticas de sala de aula dos cursos.

Em termos de estruturação, o Projeto PLE abarca atividades em quatro âmbitos: as de ensino da língua-alvo; as de aperfeiçoamento linguístico-cultural; as didático-culturais; e as de pesquisa e de formação docente. Temos, assim, no primeiro âmbito, o oferecimento de cursos de difusão do conhecimento, denominados PLE I, PLE II e 
PLE III, cada um com uma carga horária de sessenta horas semestrais, divididas em quatro aulas semanais ${ }^{4}$. No segundo âmbito, são desenvolvidas as atividades de "Puxa-Conversa", encontros semanais de duas horas-aula para a prática da conversação em português, em torno de temas; o "Cine-Clube PLE", atividade na qual os estrangeiros assistem e discutem filmes brasileiros para posterior produção escrita; o "Coral dos Estrangeiros do PLE- Abre Alas que eu quero cantar", atividade musical para o aperfeiçoamento da proficiência oral e do acento na língua portuguesa brasileira; e minicursos de temáticas diversas, oferecidos a partir das necessidades percebidas em cada turma de aprendizes. No terceiro âmbito, são realizadas excursões para visitas a pontos históricos, turísticos e culturais da região e da capital paulista, além de mostras interculturais e recitais do Coral dos Estrangeiros. Por fim, no quarto âmbito, realizamos reuniões pedagógicas semanais entre os integrantes do projeto, para discussão e encaminhamento de propostas de atividades e planejamento de aulas, além de discussões de leituras teóricas relativas ao ensino de PLE e à formação docente para esse contexto. Também são produzidos relatórios semestrais das atividades realizadas.

Quanto aos integrantes, até o momento oito licenciados em Letras e um bacharelando em Letras com habilitação em Tradutor compõem a equipe, na condição de colaboradores e bolsistas, alunos de graduação e de pós-graduação. Há uma preocupação em ter como integrantes professores já licenciados em sua LM e em uma LE, mesmo que na atual situação de reingressantes na licenciatura para outra LE. A nosso ver, essa primeira licenciatura pode garantir um processo reflexivo mais consistente sobre a formação do professor como um agente humanizador, em um contexto que envolve uma integração em torno da formação que consideramos inicial para o PLE. A única exceção é o aluno bacharelando, que atua na coordenação musical do Coral.

Em relação aos estrangeiros, temos, até o presente, aprendizes de 28 origens distintas, o que nos permite caracterizar o contexto como multilíngue e multicultural (OLIVEIRA, 2014), com alunos vindos da

\footnotetext{
${ }^{4}$ Temos por base o "Quadro Europeu Comum de Referência para Línguas", usado para descrever os objetivos a serem alcançados pelos estudantes de LEs na Europa.
} 
Argentina, Alemanha, Bolívia, Canadá, Chile, China, Colômbia, Cuba, Escócia, Espanha, Estados Unidos, França, Haiti, Itália, México, Nicarágua, Nigéria, Paraguai, Paquistão, Peru, Polônia, República Tcheca, Rússia, Serra Leoa, Síria, Tunísia, Ucrânia e Venezuela.

A seguir, caracterizaremos e apresentaremos alguns resultados da análise realizada a partir dos dados obtidos das reuniões pedagógicas gravadas em áudio, trazendo o processo reflexivo das professoras quanto ao desenvolvimento de um discurso humanizador em sua atuação docente no projeto em questão.

\section{As reuniões pedagógicas}

Nas reuniões pedagógicas realizadas pelo grupo responsável pelo projeto PLE, temos como linha norteadora a busca pela formação humanizadora e pelo desenvolvimento de oportunidades de reflexão colaborativa. Conforme já explicitado anteriormente, estamos todos em formação docente para/no projeto, ou seja, nossa formação continuada acontece simultaneamente ao desenrolar dos cursos. Esses encontros são realizados semanalmente pelo grupo e duram cerca de três horas. Neles, os participantes (professores e coordenadora/mediadora), descrevem e refletem sobre suas práticas, planejam e sugerem ações futuras e, ainda, discutem e analisam textos teóricos na área.

No excerto1, a seguir, analisamos uma reunião da qual participam as professoras Fabiana, Leandra e Marcela e a coordenadora/mediadora Helena ${ }^{5}$ Nele, constatamos o desenvolvimento de uma reflexão colaborativa a partir de leitura teórica abordando a temática das práticas humanizadoras. Essas reflexões se estendem entre as participantes, que expõem suas próprias visões e inseguranças sobre a responsabilidade que têm ao lidar com questões culturais e estereótipos, revelando um movimento de (re)construção de conceitos e de busca pela compreensão e encaminhamento das práticas ${ }^{6}$ :

\footnotetext{
${ }^{5}$ Os nomes são todos fíctícios.

${ }^{6}$ Os excertos foram transcritos preservando-se sua originalidade discursiva. As palavras e expressões escritas em caixa alta representam o destaque dado pelo próprio falante na oralidade.
} 
Helena: (...) O que vocês acharam da leitura... Se vocês estão de acordo com essa visão intercultural humanista, se vocês acrescentariam algo em relação às visões dos autores sobre língua, linguagem, competência comunicativa, competência intercultural...

Marcela: Eu achei bem interessante a parte que ele fala das atividades promotoras da PAZ comunicativa, é... Dos quatro princípios norteadores da prática da comunicação humanizadora, né, porque isso é uma coisa que a gente realmente... Principalmente nas aulas das turmas iniciantes é bem interessante a gente prestar atenção mesmo, humanizar nosso insumo linguístico, humanizar nosso VOCABULÁRIO também, nossa construção frasal, nosso jeito de falar eu acho que é bem importante, é, exercer autocontrole sobre os textos. Ele fala particularmente os escritos, mas eu acho que na sala de aula bastante na questão da fala também. O discurso do professor eu acho que influencia muito nessa questão humanizadora mesmo, dependendo de como você vai tecer o seu discurso, até no trato com o aluno isso vai influenciar muito.

Fabiana: É, se você está falando alguma, partilhando alguma coisa que você está assumindo como verdade ou não, você acabou barrando o aluno, quer dizer, você enquanto professor, quem é que vai argumentar? É nesse sentido que a gente tem que se cuidar, que tem os dois lados da moeda, principalmente com tantas nacionalidades diferentes, pensamentos diferentes. Por exemplo, no caso da síria que falou da censura, da questão da censura. Eu sinceramente, na minha experiência eu fiquei sem saber o que falar pra ela nessa questão da censura. Porque eu tava falando que dependendo dos horários, né, a novela tem cenas diferentes, à noite tem algumas cenas que não passariam à tarde, né? Mas então, pra elas só o beijo já é algo ofensivo. "Minha família está na sala e aparece mesmo na novela da tarde". Então, como que eu falo NÃO, NÃO É. Imagina, então tem que ter, assim, todo um trato, né?

Leandra: Eu acho que sim, principalmente porque sua turma é mais heterogênea. No meu caso a turma tá muito homogênea, além de ser a mesma língua materna são todas mulheres... Então a nossa intimidade tá muito, tá bem assim...estabelecida. Mas o interessante é quando você demonstra também interesse 
pela cultura do aluno, por mais diferente que ela seja, e DEMONSTRAR esse interesse e EXPLICAR que aqui é diferente, não significa que seja melhor ou pior, mas que é diferente, apenas.

Fabiana: Nossa, é diferente sim, porque eu me lembrei da questão do abraço. A gente tava discutindo um texto que mostrava um estrangeiro discutindo sobre alguns aspectos do Brasil e a gente mostrou um vídeo sobre amizade, o "Vamos brasilizar", tem dois na verdade, um comercial e uma série, que é um americano sentado numa mesa de bar, não sei se vocês já viram, da feijoada e tal... Enfim, aí tem um momento em que, na publicidade, ele chega pro vendedor e dá a mão e ele abraça né... E a gente falou disso, da questão do abraço, do contato físico. E aí a Tatiana falou: "Não, eu não acho que seja assim, na Colômbia é muito mais, as pessoas são muito mais abertas que no Brasil, as pessoas são mais...”. E eu já fiquei, eu falei assim "Nossa"... É a experiência dela, a gente fala, mas de modo geral eles acham assim que a gente abraça muito, é a concepção deles. Os chineses chegaram no primeiro dia "ah, você é a professora", TODOS vieram me abraçar e me dar um beijo, quer dizer...

Leandra: É que a gente tem uma visão unilateral né...

Fabiana: É aí que tá, entendeu? Pros chineses sim, os brasileiros abraçam e tal, mas pro colombiano não, "a gente é muito mais aberto que vocês nesse aspecto", entendeu? Então como que eu vou dizer "NÃO, BRASILEIRO ABRAÇA MESMO"? Não dá pra afirmar assim, tem que ter... Ah, e outra coisa, na própria seleção do material que a gente faz, né, porque nesse vídeo, nesse mesmo vídeo, "Vamos brasilizar", tem dois episódios, a praia e a feijoada, né... A gente escolheu a feijoada. Na verdade eu escolhi e depois eu mostrei pra eles porque eu não escolhi a praia, né. Na praia ele fala sobre a questão do biquíni e aí ele pergunta pra uma das mulheres, claro que é um contexto isolado, mas aí ele pergunta: "Ah, por que vocês têm que mostrar?" "Por que vocês têm que usar um vestido tão curto?" Aí ela falou assim, "Ah, porque é bonito na gente". Aí ele fala assim: "O que vocês acham do biquíni das americanas?" "Ah, é uma fralda". E aí ele pergunta mais ou menos assim: "E se elas usassem o biquíni de vocês nelas?" Aí ela fala assim: "Não, fica FEIO nelas, na gente fica bonito".... E eu pensei, eu não vou passar esse vídeo porque eu acho que é 
estabelecer um... Então, eu acho que na própria SELEÇÃO do material tem que ter esse trato, essa preocupação com essa questão da humanização da linguagem. Tem que ter porque senão... Helena: É, e da gente aprender a observar os efeitos daquilo que a gente trabalha em sala de aula...

Leandra: Também a gente trata de alguns conceitos muito novos como se já fizessem parte da nossa cultura e aí... Isso é muito novo pra nós, muito diferente. Então eu acho assim, esse processo da gente se reestruturar enquanto professor de português, mas não mais pra pessoa que tem a mesma língua materna que você, você se reestrutura pra um público totalmente diferente e... É um PRIVILÉGIO muito grande, você aprende também muita coisa, né, você aprende muita coisa não só da língua, da cultura do outro, mas da sua própria... Assim, é um momento de reflexão da própria língua que é muito raro de acontecer em uma sala só de brasileiros... Porque não existe essa pausa pra você pensar na sua própria cultura, na sua própria língua, porque você já tá TÃO ACOSTUMADA, sem refletir...

(Excerto 1, reunião de 2/10/2013)

$\mathrm{O}$ excerto apresentado configura-se como uma rica oportunidade de desenvolvimento de reflexão compartilhada, na qual as participantes relatam, questionam e revelam práticas e conceitos surgidos e trabalhados em sala de aula, especificamente com a turma de PLE I, da professora Fabiana. No papel de mediadora, Helena "aciona" a discussão, questionando sobre a leitura teórica realizada para a reunião, na qual se aborda fundamentalmente a visão intercultural humanista no ensino de línguas. Marcela inicia a exposição de sua opinião a respeito de conceitos trazidos pelos autores, especialmente sobre o papel do professor no estabelecimento de um discurso mais humanizador e voltado para a paz comunicativa.

A partir daí, Fabiana expõe questões que se relacionam a sua prática de sala de aula, passando a desenvolver um processo reflexivo em colaboração, no qual aborda suas fragilidades ao tratar de temas que possam representar estereótipos e choques culturais, tais como cenas de beijo na televisão e o uso de trajes de praia muito pequenos pelas brasileiras, ambos pela visão de estrangeiros - no primeiro caso, é sua aluna de origem síria que questiona a ausência de censura na 
televisão brasileira para programas exibidos em horários "familiares"; no segundo, trata-se de um vídeo que Fabiana optou por não exibir aos alunos, no qual um estrangeiro entrevista brasileiras na praia e há um episódio de preconceito em relação ao uso de biquínis. Em ambos os casos, Fabiana explicita suas inseguranças ao lidar com temáticas tão conflituosas em um contexto de ensino multicultural como o seu e ressalta a importância de o professor selecionar adequadamente os materiais de ensino, no sentido de buscar minimizar esses conflitos e promover ações mais humanizadoras e menos preconceituosas. Por sua vez, Leandra amplia o processo reflexivo, ao reconhecer que se trata de um contexto muito novo para todas, ou seja, o de "se reestruturar enquanto professor de português, mas não mais pra pessoa que tem a mesma língua materna que você, você se reestrutura pra um público totalmente diferente", algo que ela vê como um privilégio. Testemunhamos, então, um exercício de meta-humanização, ou seja, o desenvolvimento de um processo de não só buscar caminhos para compreender ou reconstruir práticas, mas também de humanizar-se profissionalmente por meio da reflexão colaborativa.

Veremos como isso ocorre em momentos distintos de duas reuniões, primeiramente no excerto 2 :

Helena: É... Em termos de quebrar preconceitos ao viver em outro país, a repressão, ter liberdade de expressão, a tolerância, e temas até que estão relacionados com o mundo, o globo terrestre mesmo, o desmatamento, a destruição, a violência, a droga... Vocês acham que existem caminhos nas aulas de PLE?

Fabiana: Sem dúvida!

Marcela: Sim!

Fabiana: Isso surgiu no Puxa-Conversa, as chinesas falaram da condição da mulher, elas diziam "na China, a mulher é menos"... na CABEÇA ...e ela fazia assim o gesto, né... lá na China, a mulher é menos que o homem, né? Então, "Ah, a China pensa assim”, ela fazia assim, ela mostrava. Quer dizer, ela olhou pra mim e pensou: "Eu sei que você não concorda com isso, mas eu tenho que te falar que lá na China a gente pensa que a mulher é menos". E eu queria explicar pra ela: "Mas, olha, aqui deste lado, DURANTE MUITO TEMPO, se pensava realmente assim, a mulher ganhou um espaço recente... 
Leandra: Aliás, o aumento da violência contra a mulher no Brasil hoje tá só revelando que a cultura ainda é machista e que quando a mulher começa a se sobressair MUITO, e muitas mais do que o homem, isso gera mais violência.

Fabiana: As próprias piadas, olha essa piada aqui é uma piada que tá dentro da nossa cultura, mas ela tá falando da mulher, da loira, quer dizer, mostrando que ela é inferior, então é extremamente ofensivo. A questão das estatísticas de violência, as músicas... Então, assim, tem muitos elementos, é, porque eu senti no comentário dela que a mulher é menos só na China. Aí caberia uma discussão GIGANTE pra falar, olha, sabe...É uma grande oportunidade, eu acredito, principalmente em uma sociedade que está em transformação, porque essa questão da mulher é muito recente na história da humanidade... Então tem esses dois lados dentro da mesma mulher, a que é romântica, eu sou romântica, entendeu, e tenho o meu salário, e pretendo trabalhar a vida inteira, mas eu sou romântica... Eu sou um exemplo porque eu tô nessa sociedade em transformação, mas essa questão do inferior, sabe, quem é inferior? Nenhum ser humano é inferior ao outro, independente de sexo... Quando ela USOU A PALAVRA INFERIOR eu pensei: "Nossa, aí uma discussão legal" e crescer com essa discussão, sabe?

Helena: Até pra você mostrar que o fato dela estar AQUI, no Brasil...

Fabiana: EU FALEI ISSO, EU FALEI! Vocês se acham inferiores, né, por serem mulheres, vocês tiveram uma coragem que EU não tive, eu não tenho, EU NÃO VOU pro outro lado do mundo, eu não iria pro Japão, pra China, EU NÃ̃ IRIA. E vocês tiveram essa coragem, de deixar a família de vocês... Só isso já mostra o quão GRANDIOSAS vocês foram, só pela coragem, que é uma grande VIRTUDE.

Leandra: Hum-hum...

Fabiana: E aí elas começaram hahaha, elas riram né...

(Excerto 2, reunião de 2/10/2013)

No excerto 3, a seguirobservamos desenvolver-se um relato sobre experiência semelhante, também na atividade de Puxa-Conversa:

Helena: Na última reunião a gente discutiu a atividade da Fabiana no Puxa-Conversa, né? E uma aluna síria fez um relato da experiência de vida dela, não foi? 
Fabiana: Hum-hum... Foi até bonito (riso)... as chinesas elas fizeram uma fila, eu acho que foi a Aline, a Aline é muçulmana... e a Ruth [aluna árabe] foi explicar que a partir do momento em que o Obama tomou o lado dos muçulmanos eles viram isso como uma coisa mais religiosa, assim ela explicou, com as palavras dela. Então começou uma perseguição com os cristãos lá também, e ela é cristã... Então a Aline sentiu isso e tomou essa iniciativa de falar, e ela explicou que ela é muçulmana e tal, né, e começou: "Mas na China não é assim, na China não é assim". E ela foi abraçar a Ruth, falar que elas iam ser amigas e tal... Eu achei muito bonita a atitude dela, foi bem surpreendente mesmo! E aí ela abraçou e todas as outras ficaram numa filinha pra abraçar ela também... Elas não são muçulmanas nem nada, mas, se sentiram assim, se comoveram mesmo, foi muito bonito...

(Excerto 3, reunião de 7/11/2013)

Nos dois excertos apresentados, 2 e 3, destacamos o processo reflexivo-humanista da professora Fabiana, que promoveu, em momentos diferentes de sua prática, oportunidades de sintonia entre culturas diversas, valorizou histórias individuais, tradições locais e procurou transformá-las em mais abrangentes, ao explicar às alunas chinesas que há uma semelhança de visões sobre a mulher entre a sociedade chinesa e a brasileira. Assim, não houve a supervalorização de uma cultura ou sociedade em detrimento da outra, promovendo a consciência de que as diferenças não devem ser ignoradas e a prática da língua para essas manifestações. Na ocasião da solidariedade entre uma muçulmana e uma cristã, de culturas e países distintos, observamos uma prática docente que proporcionou uma reorganização dos sistemas de crenças dos envolvidos na aprendizagem, advinda, principalmente, dos novos desafios educacionais e da prática do dialogismo em sala de aula.

Predomina, assim, um perfil de professor de PLE em formação que busca, sobretudo, o bem-estar dos aprendizes e a humanização da linguagem, conforme veremos a seguir, no excerto 4 :

Helena: Vocês não se sentem, é... Vamos pensar assim nesse contexto como um contexto ecológico, em termos de vida mesmo. Pra vocês existirem nesse curso vocês precisam desses 
estrangeiros... Na verdade, eles não escolheram o curso, eles deram vida pro curso, eles CRIARAM esse curso.

Marcela: É verdade, sem eles...

Fabiana: É, é MAIS AINDA..

Helena: NÓS não estaríamos aqui sem eles... Então, pra vocês como é isso? Pra manter esse curso vivo... O curso, não, o projeto, na verdade...

Fabiana: É verdade...

Helena: Porque tudo o que a gente tem feito no projeto de coisas novas, na verdade, é consequência... É como se fosse uma flor, né, uma árvore que tivesse dando flores...

Fabiana: É por isso que eu falei da sensibilidade, porque a gente tem que ter sensibilidade pra saber até que ponto que tá agradando ou não, que a gente tá atendendo às necessidades deles e, em termos de CRIATIVIDADE, assim, a gente tem que ser sempre, estar sempre buscando que a aula seguinte seja melhor do que a anterior. Então, a gente tem que ter a sensibilidade de saber o que é que deu certo e o que não deu justamente pra mantê-los VIVOS no curso, até porque virão outros... Então, se as aulas não forem motivadoras, a gente corre o risco da perda do interesse a longo prazo...

Leandra: E não só de estar agradando, mas, é, não sei se a expressão seria esta, DEIXÁ-LOS A VONTADE... Eu acho que a relação que a gente cria inconscientemente é fazer com que eles se sintam como se estivessem em casa... Porque, bom, eu nunca saí do país, mas eu acho que, se eu ficasse fora, depois de um certo tempo eu ia procurar qualquer coisa que me matasse a saudade...

Fabiana: Hã-hã... LEMBRAR DE CASA, exatamente... Isso é verdade, quando aparecem expressões de saudade, às vezes em música, coisa e tal... Deles se reconhecerem imediatamente em textos também.

Leandra: É uma relação muito mais forte do que da aula padrão... Assim eu vejo... É uma relação FORTE, mas, assim, quando você tá num ensino padronizado, tradicional, você tem alunos muito mais jovens, geralmente, e inexperientes que você porque eles não tiveram ainda tempo suficiente pra ter uma experiência maior em vários aspectos...Então a preocupação é em FORMAR esse cidadão pra vida deles, pro mercado de trabalho, sempre lembrando que ele é um brasileiro, que provavelmente vai continuar aqui no Brasil. Já eles, os 
estrangeiros, eles já têm uma experiência, então acontece mesmo uma troca e isso torna o laço ainda mais... afetivo... Essa troca de cultura, de experiência, muitos são mais velhos que a gente, mais experientes, já saíram do país mais de uma vez. Então é muito mais forte, muito mais intenso.

Marcela: Eu acho que os laços de amizade que a gente acaba BUSCANDO FORTALECER entre nós e eles e entre eles mesmos... Isso acaba sendo maior, eu acho que a gente acaba se ABRINDO MAIS nesse contexto do que a gente faz em uma sala de aula regular com adolescentes, por exemplo. E eu tenho essa questão assim de me colocar muito à disposição deles pra qualquer coisa que eles precisem... A gente dá essa abertura e eles se sentem muito também À VONTADE para conversar com a gente sobre assuntos pessoais, pra contar coisas deles, mas sem a intenção de ter reciprocidade, sem esperar que a minha professora me conte a vida dela... Eu acho que existe isso, essa confiança...

(Excerto 4, reunião de 7/11/2013)

Finalizando esta discussão sobre as evidências de práticas de ensino e de formação docente humanizadora encontradas nas reuniões pedagógicas analisadas, podemos afirmar que alguns dos conceitos presentes na interação acima representam aquilo que fomenta a atividade docente das professoras em questão: sensibilidade, criatividade, afetividade, intensidade, disposição, vontade, reciprocidade e confiança. Podemos certamente dizer que o papel da mediadora é fundamental, no sentido de acionar debates e instaurar um ambiente propício à reflexão compartilhada, em busca de uma formação docente para/ nesse contexto inovador de ensino para todas as envolvidas.

\section{Resultados de análise e considerações finais}

As reuniões pedagógicas tem como linha norteadora a busca pela formação humanizadora e pelo desenvolvimento de oportunidades de reflexão colaborativa entre os participantes. Como resultados, os excertos analisados podem sugerir que essas reuniões proporcionam momentos de intensa reflexão sobre a importância maior da construção 
de discursos humanizadores no ensino de PLE, em direção à possibilidade de um mundo melhor ou da não-violência. Comprova-se também, nas passagens analisadas, o relato de vivências de uma educação inovadora e em movimento para o futuro, na qual os questionamentos sobre as tradições são fundamentais para o desenvolvimento de uma reflexão crítica sobre sistemas educacionais e suas premissas.

Acreditamos no trabalho que vem sendo desenvolvido nesse projeto porque temos por premissa que visões que inferiorizam culturas, julgam e generalizam hábitos a partir de uma cultura ideal (geralmente a cultura materna) matam a interculturalidade (GOMES DE MATOS, 2010) e desconsideram valores universais, como a preservação da vida, da paz e da justiça, que devem perpassar todas as línguas e culturas.

Vivemos em um tempo marcado por transformações, processos de globalização e avanços tecnológicos muito rápidos, que afetam o mundo, as fronteiras e a maneira como pensamos e vivemos. Consequentemente, temos uma nova constituição dos indivíduos e de suas identidades, afetando, igualmente, as formações dos discursos. $\mathrm{O}$ preparo docente na promoção do ensino/aprendizagem de PLE deve ser tratado, assim, como questão fundamental nos currículos das universidades que almejam uma formação docente para novos contextos, encarando as novas demandas de internacionalização do ensino. No Brasil, ainda se fala timidamente sobre isso, embora a questão mereça destaque na visão contemporânea dos documentos oficiais. Não podemos pensar em interculturalidade nem mesmo em atuar de maneira sociopolitizadora como professores de PLE sem contemplar a formalização dessa formação e as universidades devem ter condições de proporcionar sua implantação de maneira eficaz, encarando as novas demandas de internacionalização do ensino.

A questão da ruptura de fronteiras linguísticas em torno da valorização de línguas não hegemônicas, como é o caso do português, língua-alvo de nosso projeto, vem mostrando resultados positivos, tomando como parâmetro o interesse de estrangeiros das mais diversas partes do mundo pelo Brasil, pela aprendizagem de PLE e pela cultura brasileira, o que resulta em oportunidades para o ensino e a formação de professores de PLE em um contexto universitário onde, tradicionalmente, não se oferece essa formação. 
Conforme nos propusemos a fazer, tratamos de questões de ensino e de formação docente em um cenário geográfico e linguísticocultural que se constitui da sala de aula de aula de PLE em um contexto acadêmico. Acreditamos, ainda, que podemos contribuir para o estabelecimento de um espaço propício a novos estudos sobre formação de professores de línguas e de pesquisadores-humanizadores em harmonia com os parâmetros da Declaração Universal dos Direitos Linguísticos, na trajetória de pesquisas em LA.

\section{Referências}

ALMEIDA FILHO, José C. P. Maneiras de credenciar-se na área de ensino de português a falantes de outras línguas. In: ALMEIDA FILHO, José C. P.; CUNHA, Maria J. C. (Orgs.). Projetos iniciais em português para falantes de outras línguas. Campinas, Pontes: 2007. p. 33-37.

- Questões da interlíngua de aprendizes de português a partir ou com a interposição do espanhol (língua muito próxima). In: SIMÕES, Antonio R. M.; CARVALHO, Ana M.; WIEDMANN, Lyris. (Orgs.). Português para falantes de espanhol/ for Spanish speakers. Campinas: Pontes, 2004. p. 183-191.

ANDRÉ, M. E. D. A. Etnografia da prática escolar. Campinas: Papirus, 2000. p. 27-31.

KFOURI- KANEOYA, Marta L. C. A formação de professoras de línguas para/em contexto mediado pelo computador (teletandem): um diálogo entre crenças, discurso e reflexão profissional. Tese (Doutorado em Linguística Aplicada) - Instituto de Biociências, Letras e Ciências Exatas, UNESP: São José do Rio Preto, SP, 2008.

CUNHA, Maria. J. C. O português para falantes de outras línguas: redefinindo tipos e conceitos. In: ALMEIDA FILHO, José C. P.; CUNHA, Maria .J. C. (Orgs.). Projetos iniciais em português para falantes de outras línguas. Campinas, Pontes: 2007. p. 13- 31. 
OLIVEIRA, Luciana C. Language teaching in multilingual contexts. Revista Brasileira de Linguística Aplicada, v. 14, n.2, p. 265-270, 2014.

FAIRCLOUGH, Norman. Language and power. London: Longman, 2001.

GOMES DE MATOS, Francisco. Como usar uma linguagem humanizadora: orientação para professores de línguas estrangeiras. In: MOTA, Kátia M.; SCHEYERL, Denise. (Orgs.). Recortes interculturais na sala de aula de línguas estrangeiras. Salvador: EDUFBA, 2010. p. 24-36.

LITTLE, David. A aprendizagem de línguas em tandem e a autonomia do aprendente. In: DELILLE, Karl H.; CHICHORRO, Adelaide. (Eds.). Aprendizagem autônoma de línguas em Tandem. Lisboa: Colibri, 2002, p. 27-35.

MOTA, Kátia M.S. Incluindo as diferenças, resgatando o coletivo novas perspectivas multiculturais no ensino de línguas estrangeiras. In: MOTA, Kátia, M.; SCHEYERL, Denise. (Orgs.). Recortes interculturais na sala de aula de línguas estrangeiras. Salvador: EDUFBA, 2010. p. 37-62.

MURPHEY, Tim.; et al. Emotional belonging precedes learning. In: BARCELOS, Ana Maria F.; COELHO, Hilda .S. H. (Orgs.). Emoções, reflexões e (trans)form(ações) de alunos, professores e formadores de professores de línguas. Campinas: Pontes, 2010. p. 43-56.

UNESCO. Declaração universal dos direitos linguísticos. Barcelona, Espanha, 1996.

Submetido em: 21/10/2014 Aceito em: 16/06/2015

Title: The language teacher as a humanizer and interculturalist agent in a Portuguese as a foreign language teaching context: implications to the teacher education 